\title{
A Comparison of GenCade, Pelnard-Considere, and LITPACK
}

\author{
by Sung-Chan Kim, Richard Styles, Julie Rosati, Yan Ding, \\ and Rusty Permenter
}

PURPOSE: The purpose of this Coastal and Hydraulics Engineering Technical Note (CHETN) is to investigate the basic physics and numerical code of GenCade by running a series of simplified test cases and comparing the results to another numerical shoreline evolution model and an analytical solution. The complementary numerical code is the widely used shoreline evolution model LITPACK. The analytical model is the original solution derived by Pelnard-Considere (1956). The underlying assumption in all three approaches is a beach profile of constant shape so that shoreline change is driven by long-shore transport processes and a combination of independent sediment sources or sinks (e.g., sea level change, subsidence). The CHETN presents a descriptive overview of the theory behind the models followed by an inter-comparison using a set of four test cases involving shoreline change in the vicinity of idealized coastal structures and a beach nourishment. GenCade shows good agreement with LITPACK, and both models compare well to the analytical solution for these idealized cases. The GenCade results indicate that the underlying numerical code and basic physical process are consistent with other widely used shoreline modeling systems.

INTRODUCTION: Mathematical modeling of shoreline change is a powerful engineering technique for understanding and predicting the long-term evolution of a beach (Hanson 1989). Mathematical models provide a quantitative means of describing shoreline evolution observed at groins, jetties, and detached breakwaters (Larson et al. 1997).

One class of models designed to predict shoreline evolution driven by long-shore transport processes is based on the so-called one-line theory. In the one-line theory, the beach profile is assumed to maintain an equilibrium shape, implying that all bottom contours are parallel. Longshore transport is assumed to occur uniformly across the entire beach profile, from the top of the berm crest down to a certain critical depth, $D$, called the depth of closure. No sand is presumed to move alongshore in the region seaward of $D$ (Larson et al. 1987).

Pelnard-Considere (1956) derived the first analytical solutions to describe shoreline change by assuming that the beach profile always remains in equilibrium so that cross-shore fluxes are neglected. He further assumes no currents, constant wave direction, small angle of wave incidence, and a linear relation between wave incidence angle and littoral drift. These restrictions greatly simplify the dynamics allowing for an analytical solution, which forms the basis for testing the basic functionality of higher-order numerical models that incorporate more realistic physics.

LITPACK is a software package developed by DHI and consists of a suite of numerical codes for modeling coastline evolution and sediment transport along quasi-uniform beaches (https://www.mikepoweredbydhi.com/products/litpack). LITPACK also uses a wave-driven 
sediment transport algorithm to compute the fluxes but includes additional processes such as longshore currents. LITPACK is run within the Mike Zero 2011 software package.

GenCade is a numerical model that calculates shoreline change, wave-induced long-shore sand transport, and morphology change on a local to regional scale and can be applied as a planning or engineering tool (Frey et al. 2012). The model combines GENESIS (Hanson 1989), a shoreline change model with Cascade, a sediment budget model used to investigate sand bypassing at inlets and other structures (Larson et al. 2003).

In a study by Townsend et al. (2014), a comparison to similar one-line shoreline models (LITPACK) demonstrated that GenCade performed qualitatively similar to the other models. However, the comparison demonstrated areas where GenCade could be improved. This study expanded upon the previous study by re-examining the coding and algorithms, especially dealing with boundary conditions, applied in GenCade to demonstrate how GenCade provides better accommodations of processes for varying configurations.

BACKGROUND: The underlying assumption in all three modeling approaches is that the time rate of change of total volume is controlled through spatial gradients in the sediment flux. Shoreline change is calculated using a conservation equation in a control volume, in which sediment flux is restricted to a fixed cross-shore profile but the alongshore flux can vary. Sediment entering or exiting the control volume is compensated by temporal changes in shoreline position. Under these assumptions the conservation of sediment volume can be written as

$$
\frac{\partial y}{\partial t}=\frac{-1}{D_{S}}\left(\frac{\partial Q_{l}}{\partial x}\right)
$$

where $y=$ cross-shore coordinate and represents the shoreline position, $t=$ time, $x=$ the alongshore coordinate, $Q_{l}=$ longshore transport rate, and $D_{s}=$ total closure depth. Equation (1) represents the basic governing equation for all three modeling approaches. Differences appear in the form of the longshore sediment transport formulas. Note that GenCade and LITPACK also contain terms to represent other processes such as sea level rise and subsidence, but this CHETN focuses on shoreline change due to gradients in the alongshore flux for small angle inicident waves.

Pelnard-Considere Model. The Pelnard-Considere equation results from combining the conservation of sediment equation with the linearized transport equation. Because the PelnardConsidere equation has been modified over the years, a more detailed description of the theoretical approach is presented here for completeness. The equation for conservation of sediment is the same as Equation (1), and sediment transport is based on an earlier form of the Coastal Engineering Research Center (CERC 1984) formula

$$
Q=\frac{K}{8} \frac{H_{b}^{2.5} \sqrt{g / \kappa}}{(1-p)(s-1)} \frac{\sin 2\left(\beta-\alpha_{b}\right)}{2}
$$

in which $Q$ is the total alongshore volumetric sediment transport rate, $K$ is the sediment transport coefficient, $H_{b}$ is the breaking wave height, $p$ is the sediment porosity, $\kappa$ is the ratio of wave height to water depth within the surf zone, $\alpha_{b}$ is the azimuth from which the wave propagates, and $\beta$ is 
the azimuth of the outward beach normal, and $s=$ relative sediment density $\left(=\rho_{s} / \rho\right), \rho_{s}=$ sediment density, and $\rho=$ fluid density. Differentiating (2) with respect to $x$ gives

$$
\frac{\partial Q}{\partial x}=\frac{K}{8} \frac{H_{b} 2.5 \sqrt{g / \kappa}}{(1-p)(s-1)} \cos 2\left(\beta-\alpha_{b}\right) \frac{\partial \beta}{\partial x}
$$

The parameter $\beta$ can be linearized because of the assumed small changes in shoreline orientation giving

$$
\beta=\mu-\frac{\pi}{2}-\tan ^{-1}\left(\frac{\partial y}{\partial x}\right) \approx \mu-\frac{\pi}{2}-\frac{\partial y}{\partial x}
$$

Considering the wave approach angle $\left(\beta-\alpha_{b}\right)$ to be small such that $\cos 2\left(\beta-\alpha_{b}\right) \approx 1$, the final result is

$$
\frac{\partial Q}{\partial x}=\frac{K H_{b}^{2.5 \sqrt{g / \kappa}}}{8(1-p)(s-1)} \frac{\partial^{2} y}{\partial x^{2}}
$$

Combining Equations 1 and 5 results in a single equation that describes the planform evolution for a shoreline initially out of equilibrium

$$
\frac{\partial y}{\partial t}=G \frac{\partial^{2} y}{\partial x^{2}}
$$

where $G$ is the longshore diffusivity

$$
G=\frac{K H_{b}^{2.5 \sqrt{g / \kappa}}}{g D_{S}(1-p)(s-1)}
$$

Equation 6 is the one-dimensional diffusion equation whose solution will vary depending upon the initial and boundary conditions. The boundary conditions for each of the four test cases lead to different solutions to Equation 6 and are not listed here. Larson et al. (1997) present analytical solutions for Equation 6 using a modified form of the longshore sediment transport equation, but the general technique is applicable to the test cases presented here. The analytical solutions provide a closed-formed result that can be used to verify higher-fidelity numerical algorithms for simplified coastal geometries.

GenCade Model. GenCade uses a more advanced version of the CERC formula that includes additional terms that account for alongshore gradients in wave height, as well as tidal or winddriven longshore currents (Frey et al. 2012). In this way, GenCade can model processes such as diffraction near coastal structures or inlets that are associated with changes in wave height. With appropriate boundary and initial conditions GenCade computes the evolution of shoreline position along an arbitrary beach front. Frey et al. (2012) provides further details regarding the theory and solution procedure for GenCade.

LITPACK Model. The LITPACK longshore sediment transport calculations are more complex, and involve greater analysis of waves and corresponding radiation stress fields. This enables the user 
to determine the longshore current and the distribution of sediment concentration in the vertical direction, as well as calculate the sediment transport and the morphological changes. A description of the model package and equations can be found in Kerper et al. (2002) and references therein.

Test Cases. The category of idealized model domains developed for the standardized benchmark cases includes a straight shoreline as the analytical model is not designed for more complex geometries. The cases tested include the following:

- Case 1. Straight shoreline, single groin

- Case 2. Straight shoreline, beach fill

- Case 3. Straight shoreline, beach fill and groin

- Case 4. Straight shoreline, two identical groins.

Townsend et al. (2014) included Case 1 and Case 2. In this study, Case 3 and Case 4 were added. Table 1 lists common parameters and forcing applied for each case. Model-specific parameters were $\mathrm{K}_{1}$ and $\mathrm{K}_{2}$ varied to enable comparison.

\begin{tabular}{||l|l|}
\hline \hline Table 1. Parameters for all benchmark cases. \\
\hline \hline Parameter & Value \\
\hline Starting shoreline position & $100 \mathrm{~m}$ from and parallel to the grid \\
\hline Offshore wave height & $0.75 \mathrm{~m}$ \\
\hline Wave period & $8 \mathrm{~s}$ \\
\hline Incident deep water wave angle & $+15 \mathrm{deg}$ \\
\hline Mean grain size diameter & $0.25 \mathrm{~mm}$ \\
\hline Active beach height & $11 \mathrm{~m}(1 \mathrm{~m}$ berm height $+10 \mathrm{~m}$ depth of closure) \\
\hline Simulation period & $2 \mathrm{yr}$ \\
\hline $\mathrm{K}_{1}$ (test cases $1,2,3$, and 4$)$ & $0.20,0.30,0.20$, and 0.25 \\
\hline $\mathrm{K}_{2}$ (test cases $1,2,3$, and 4$)$ & $0.10,0.10,0.15$, and 0.20 \\
\hline \hline
\end{tabular}

MODEL COMPARISONS: The model runs consist of an initially straight coastline that contains a structure of a recent beach fill. The model comparisons focus on the final shoreline position. To provide more information on the model solution, the time evolution of shoreline position is illustrated using the GenCade results.

Case 1: Straight shoreline, single groin. This case includes a straight shoreline with a single $75 \mathrm{~m}$ long groin (175 m from the grid origin) at the center of the domain (Figure 1). Groins are common coastal structures that represent an obstruction to longshore transport as sediment is bypassed around their tip. LITPACK does not calculate wave diffraction around groins. However, the software does include diffraction around jetties, so the groins were modeled as jetties. The presence of the groin disrupts the alongshore sediment flux causing the observed pattern. Sediment is deposited on the updrift side of the groin causing the original shoreline to shift seaward. Eventually, the updrift shoreline reaches the tip of the groin, and the alongshore flux is no longer inhibited. The shoreline position does not advance seaward form this time forward. The time history of this process is illustrated in Figure 2 for GenCade. In LITPACK, the only boundary condition is the fixed shoreline angle. Compared to GenCade and the Pelnard-Considere solution, LITPACK shows greater deposition on the updrift side and correspondingly greater erosion on the 
downdrift side. Compared to LITPACK and the Pelnard-Considere solution, GenCade shows a smoother profiler due to greater diffusion near the structure. Both GenCade and LITPACK overpredict the advancement and the retreat of shoreline around the groin compared to the PelnardConsidere solution. Overall, the comparison among the three models is good but with some diffusion at the groin in GenCade that is not present in LITPACK.

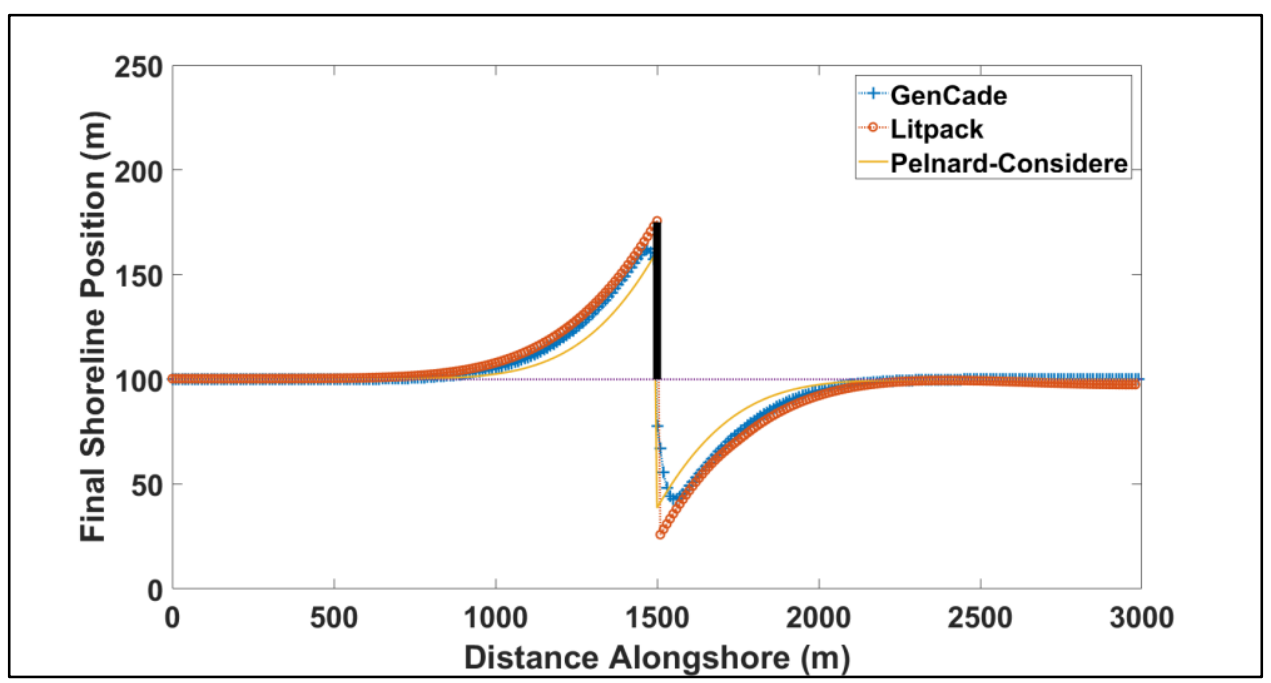

Figure 1. Calculated final shoreline position for a straight shoreline with a $75 \mathrm{~m}$ groin.

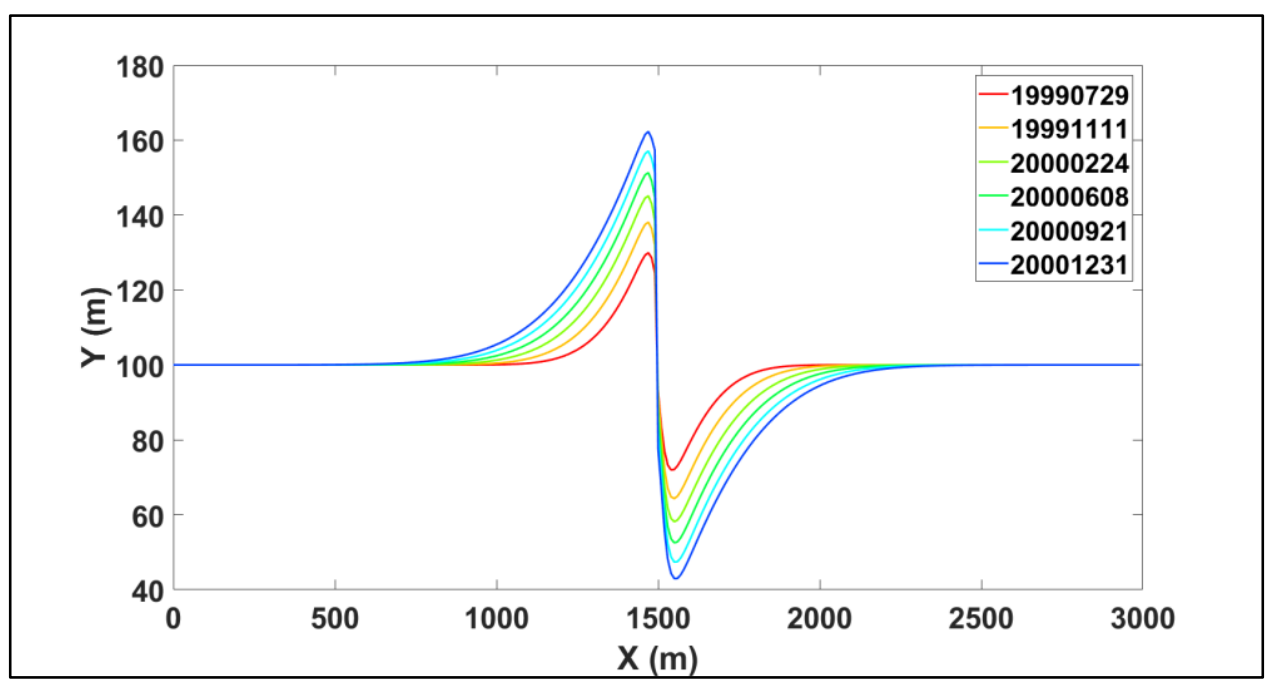

Figure 2. Time progress of GenCade model simulation for Case 1. This demonstrates seaward progradation of the shoreline along the updrift side of the groin and the retreat of the shoreline along the downdrift side of the groin. Lines represent times approximately 105 days apart. The simulation starts at 19990101.

Case 2: Straight shoreline, beach fill. Case 2 consists of a simulated beach fill to evaluate shoreline evolution after project completion (Figure 3). In GenCade, the beach fill project was initiated 2 months into the simulation and included an additional 2-month period of construction that added $50 \mathrm{~m}$ of berm width over an alongshore distance of $500 \mathrm{~m}$. Upon beach fill completion (i.e., after 2 months of pumping fill material onto the berm), no additional material was added. As time progresses, the shoreline retreats from the seaward edge of the fill (Figure 4). The shoreline 
advance method was employed in LITPACK, with the starting shoreline incorporating the $500 \mathrm{~m}$ $\times 50 \mathrm{~m}$ fill. Results from all three models show the lateral diffusion of the beach fill material along the shoreline. It is also evident that the greatest deviation from the background transport rate occurs at the fill transition zones. There was visible accretion to the both sides of the shoreline retreat, with erosion at the site of the greatest shoreline retreat. Unlike Townsend et al. (2014) in which GenCade underpredicted shoreline advancement, the current setup resulted in comparable results with LITPACK. As in Case 1, both GenCade and LITPACK solutions compare well to the PelnardConsidere analytical solution.

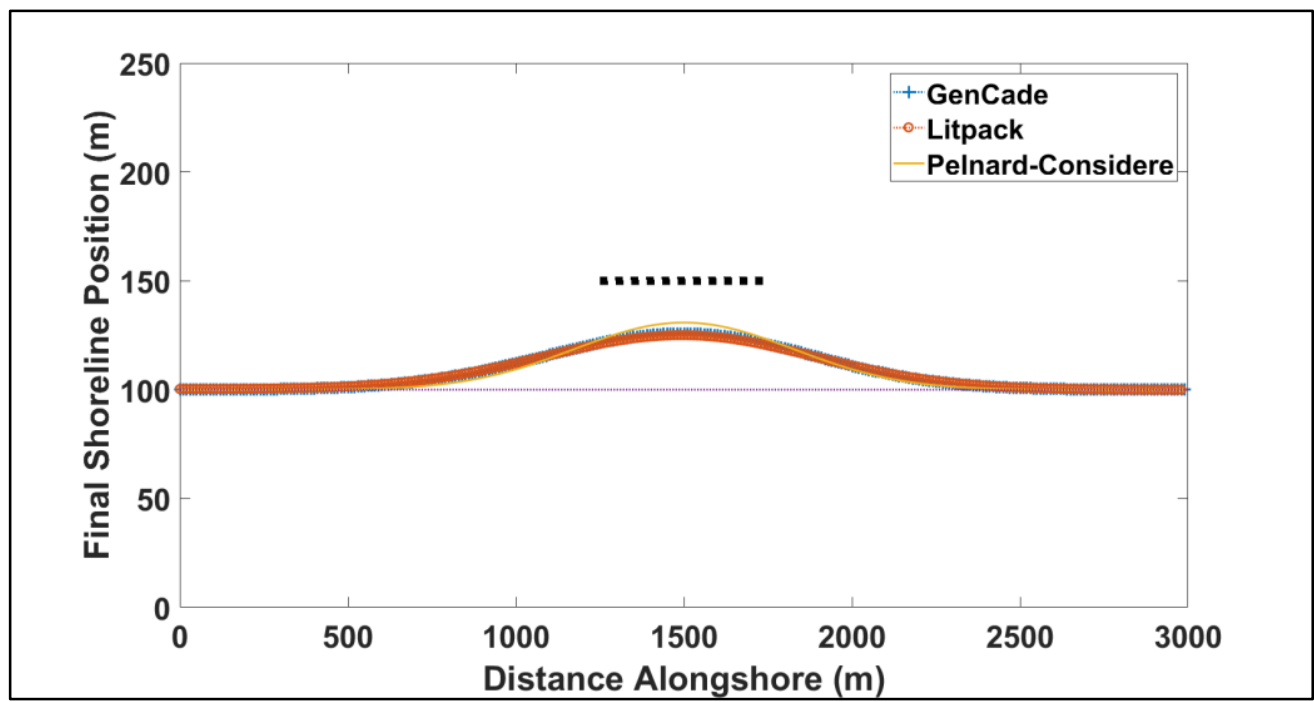

Figure 3. Calculated final shoreline positions for a straight shoreline with beach fill/shoreline advance. Thick, black dotted line between $1250 \mathrm{~m}$ and $1750 \mathrm{~m}$ represents the offshore limit of an initially placed $500 \mathrm{~m} \times 50 \mathrm{~m}$ beach fill.

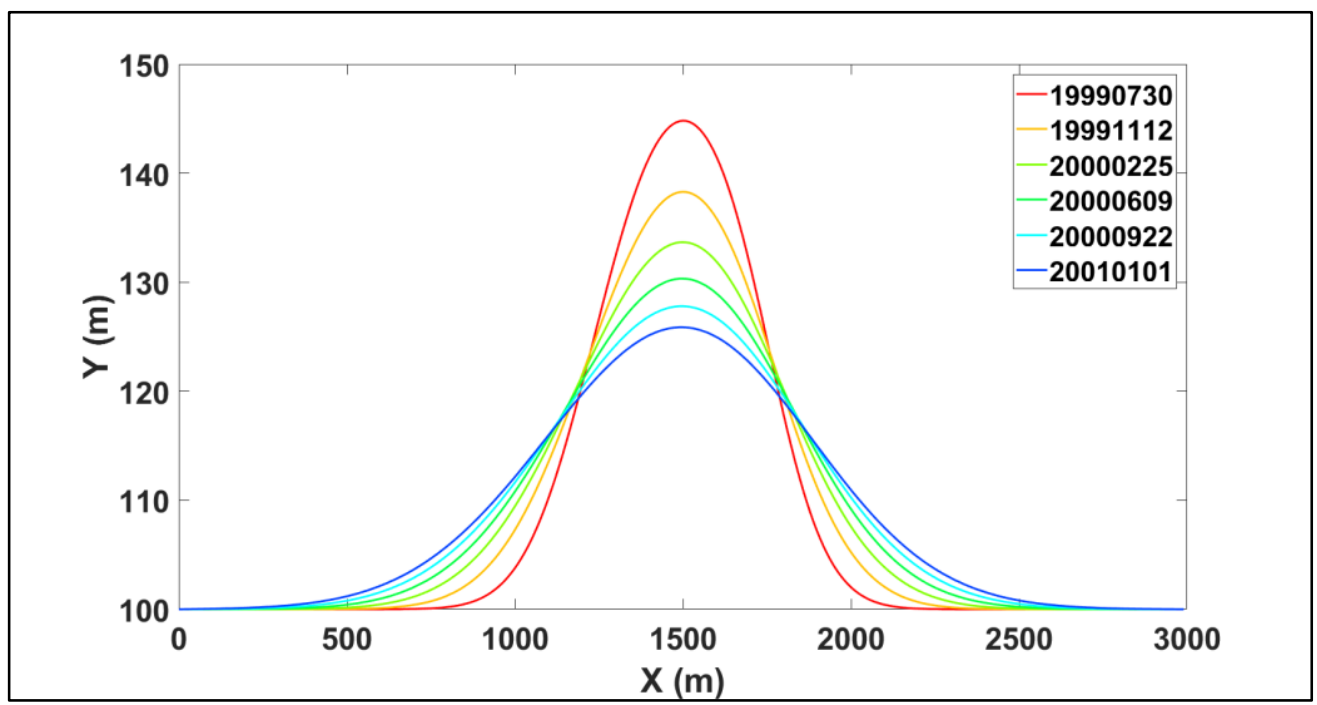

Figure 4. Time progress of GenCade model simulation for Case 2. Lines represent times approximately 105 days apart. The simulation starts at 19990101. 
Case 3: Straight shoreline, beach fill and groin. In this case, a $500 \mathrm{~m} \times 50 \mathrm{~m}$ beach fill is added immediately to the left of a $75 \mathrm{~m}$ groin. As with the single groin case, sediment accretion and the resulting shoreline progradation occurs on the updrift side of the structure as the transport rates decrease significantly at the groin (Figure 5). The initial beach fill, however, results in less erosion downdrift of the groin. Compared to both GenCade and LITPACK, the Pelnard-Considere model shows significant impoundment at the center of the beach fill location, suggesting that the analytical solution overestimates shoreline advance (Figure 5). As time progresses, beach fill updrift of the groin predicted by GenCade appears similar to Case 1 (groin without beach fill), but is less concave and more diffuse due to the extra sand supply along the updrift side (Figure 6). The GenCade results compare well to LITPACK except for the greater diffusion downdrift of the groin.

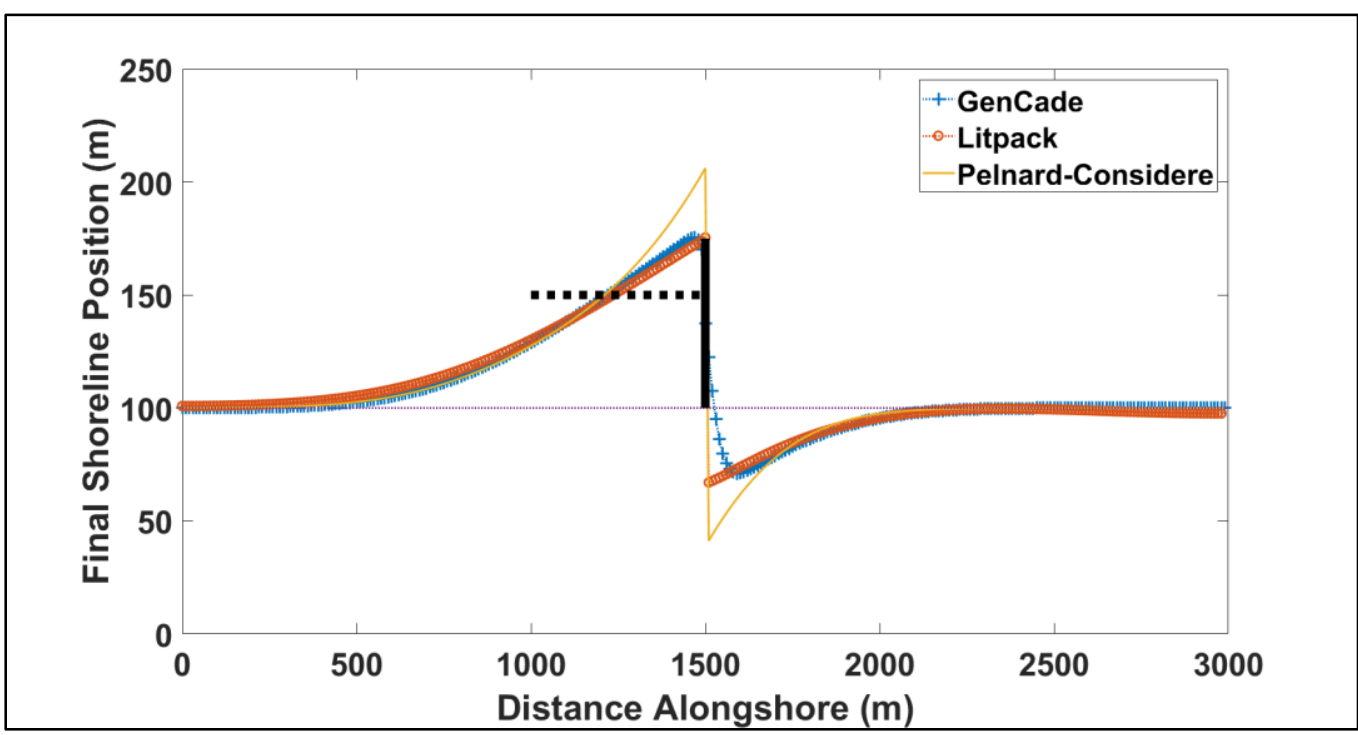

Figure 5. Calculated final shoreline positions for a straight shoreline with a beach fill/shoreline advance and groin. Thick, black straight line represents groin and thick black dotted line represents $500 \mathrm{~m} \times 50 \mathrm{~m}$ beach fill added to the groin.

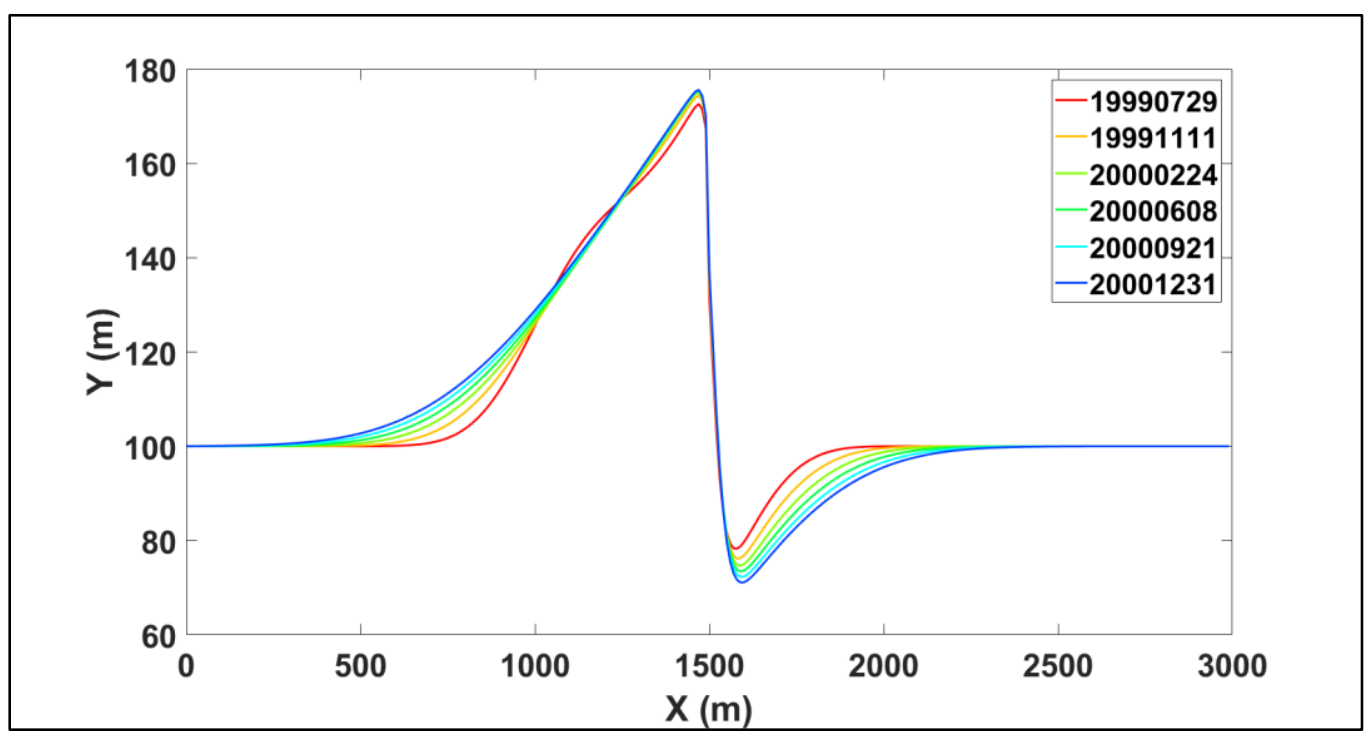

Figure 6. Time progress of GenCade model simulation for Case 3 Lines represent times approximately 105 days apart. The simulation starts at 19990101. 
Case 4: Straight shoreline, two identical groins. This case involves two interacting, identical $75 \mathrm{~m}$ long groins, spaced $500 \mathrm{~m}$ apart. As in Case 1, accretion occurs updrift of each groin, and erosion occurs downdrift of each groin. The two groins were simulated as jetties in LITPACK to account for wave diffraction and yield a more representative result. Also as in Case 1, the fixed angle boundary condition in LITPACK resulted in less impoundment than in GenCade, with a final shoreline much more in line with that of the Pelnard-Considere solution (Figure 7). As time progresses, the shoreline progradation along the updrift side of the first groin, and the shoreline retreat along the downdrift side of the second groin look closer to those of a single groin (Case 1) (Figure 8).

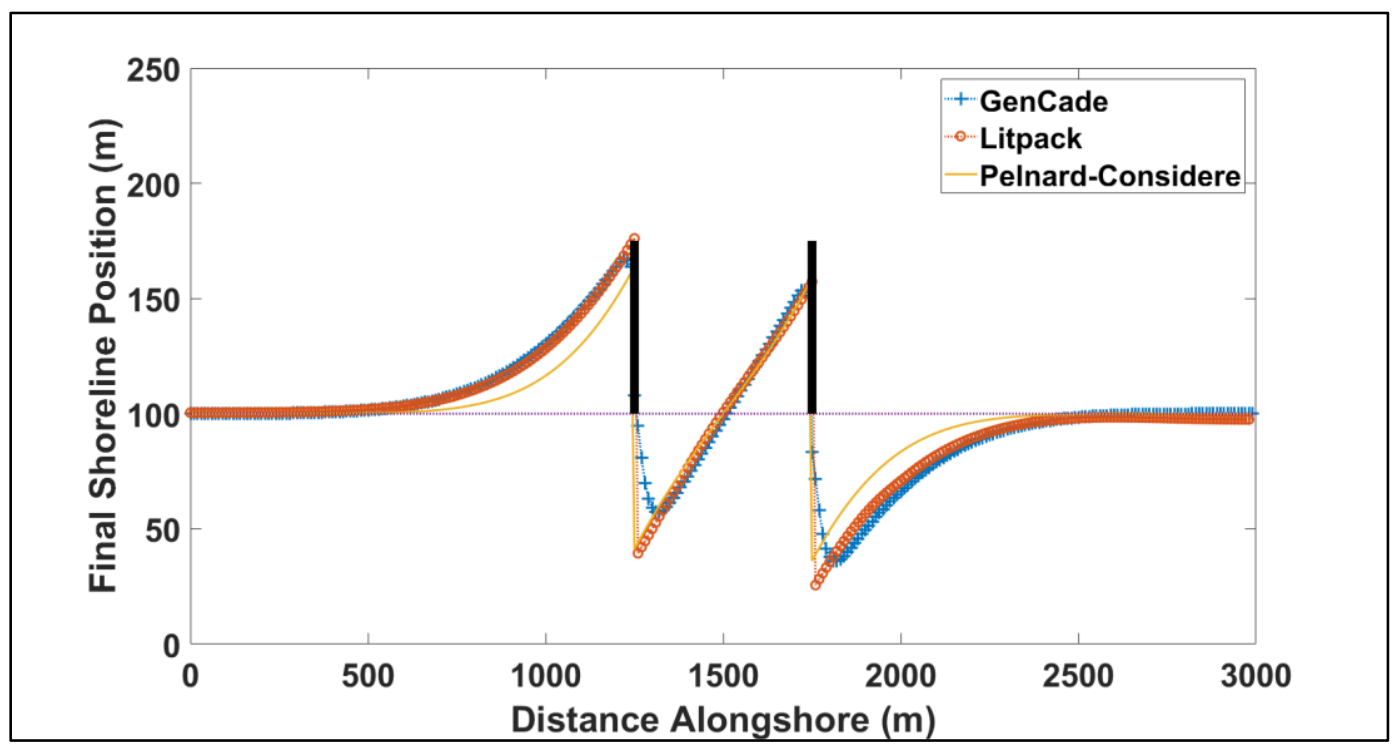

Figure 7. Calculated shoreline position for a straight shoreline with two identical $75 \mathrm{~m}$ groins. Two thick, black lines at $1250 \mathrm{~m}$ and $1750 \mathrm{~m}$ alongshore represent two $75 \mathrm{~m}$ long groins.

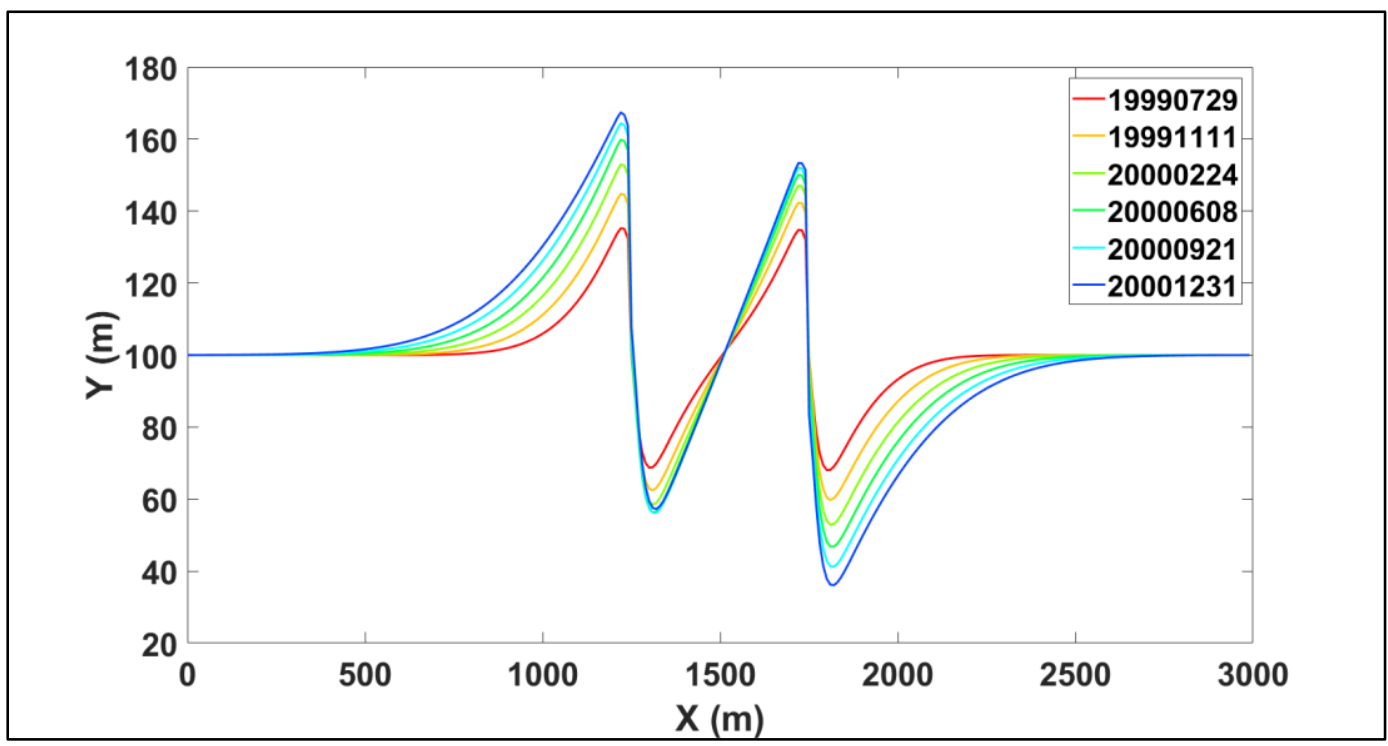

Figure 8. Time progress of GenCade model simulation for Case 4. Lines represent times approximately 105 days apart. The simulation starts at 19990101. 
SUMMARY: The listed test cases show GenCade is a useful tool for shoreline change prediction. The solutions reasonably reproduce analytical solutions of Pelnard-Considere and are comparable with similar numerical model such as LITPACK. In LITPACK, the default update of the coastline position at each time-step is based on the instantaneous drift for each event. This may lead to instabilities if there are sharp transitions within the domain. In such cases, it is advantageous to use the average drift update. This approach was adopted for Case 3 to correct for some instabilities that developed at the groin. The average drift update did lead to a stable and fairly accurate representation in comparison to the analytical solution.

Pelnard-Considere's analytical solution is the basis for most one-line shoreline models including GenCade and LITPACK. The replication of the Pelnard-Considere solutions for varying cases in the study suggests GenCade can provide reasonably accurate prediction for shoreline change.

Notable differences between the models that can influence the results include the following:

- LITPACK does not assume wave diffraction for groins. As such, a jetty structure was modeled instead, which does include wave diffraction.

- GenCade allows for user-specified, time-series beach placements starting after the simulation start time. Beach fill in LITPACK is added to the initial shoreline position for analysis. Results from both models were very similar to the analytical solution.

- LITPACK includes only a fixed shoreline angle boundary condition. This was noted as a possible key feature driving differences in model results in the immediate vicinity of coastal structures.

ADDITIONAL INFORMATION: This CHETN was prepared as part of the US Army Corps of Engineers (USACE), Coastal Inlets Research Program (CIRP), by Julie Rosati, Sung-Chan Kim, Richard Styles, Yan Ding, and Rusty Permenter, US Army Engineer Research and Development Center, Coastal and Hydraulics Laboratory, Vicksburg, MS. Questions pertaining to this CHETN may be directed to Sung-Chan Kim (Sung-Chan.Kim@usace.army.mil); the USACE CIRP Program Manager, Tanya M. Beck (Tanya.M.Beck@usace.army.mil). Additional information regarding CIRP may be obtained from the CIRP web site http://cirp.usace.army.mill.

This ERDC/CHL CHETN should be cited as follows:

Kim, Sung-Chan, Richard Styles, Julie Rosati, Yan Ding, and Rusty Permenter. 2020. Comparison of GenCade, Pelnard-Considere, and LITPACK. ERDC/CHL CHETN-IV-124. Vicksburg, MS: US Army Engineer Research and Development Center. http://dx.doi.org/10.21079/11681/35933

\section{REFERENCES}

CERC (Coastal Engineering Research Center). 1984. Shore Protection Manual. Volume 1 and Volume 2. Vicksburg, MS: Department of the Army, Waterways Experiment Station, Corps of Engineers.

Frey, A. E., K. J. Connell, H. Hanson, M. Larson, R. C. Thomas, S. Munger, and A. Zundel. 2012. GenCade Version 1 Model Theory and User's Guide. ERDC/CHL-TR-12-25. Vicksburg, MS: US Army Engineer Research and Development Center.

Hanson, H. 1989. “GENESIS: A Generalized Shoreline Change Numerical Model.” J. Coastal Research 5(1): 1-27. 
Kerper, R. D., I. Broker, C. E. Damgaard, and J. A. Zysterman. 2002. "Application of Coastal Modeling Systems in Support of Integrated Coastal Zone Management." Proceedings of Coastal Disasters Conference, San Diego, California, 28-42.

Larson, M., H. Hanson, and N. C. Kraus. 1987. Analytical Solutions of the One-Line Model of Shoreline Change. CERC-TR-87-15. Vicksburg, MS: Coastal Engineering Research Center.

Larson, M., H. Hanson, and N. C. Kraus. 1997. "Analytical Solutions of One-Line Model for Shoreline Change near Coastal Structures." J. Waterway, Port, Coastal, and Ocean Engineering 123(4): 180-191.

Larson, M., N. C. Kraus, and H. Hanson. 2003. "Simulation of Regional Longshore Sediment Transport and Coastal Evolution-The 'Cascade' Model.” Coastal Engineering 2002: Solving Coastal Conundrums, 2612-2624. https://www.worldscientific.com/worldscibooks/10.1142/5165

Pelnard-Considere, R. 1956. "Essai de Theorie de L'evolution des Formes de Rivage en Plages de Sable et de Galets." Les Energies de la Mer: Compte Rendu Des Quatriemes Journees de L'hydraulique, Paris 13, 14 and 15 Juin 1956; Question III, rapport 1, 74-1-10.

Townsend, K. E., R. C. Thomas, and A. E. Frey. 2014. Shoreline Change Modeling Using One-Line Models: Application and Comparison of GenCade, Unibest, and Litpak. ERDC/CHL CHETN-IV-102. Vicksburg, MS: US Army Engineer Research and Development Center.

NOTE: The contents of this technical note are not to be used for advertising, publication, or promotional purposes. Citation of trade names does not constitute an official endorsement or approval of the use of such products. 